\title{
Non-Articular Felty Syndrome Refractory to Granulocyte Colony-Stimulating Factor Therapy
}

\author{
Hasham Saeed $^{1}$, Chidinma Ejikeme ${ }^{1}$, Marina Tucktuck ${ }^{2}$, Qirat Jawed ${ }^{1}$, William Kessler ${ }^{3}$ \\ 1. Internal Medicine, Rutgers Health/Trinitas Regional Medical Center, Elizabeth, USA 2. Internal Medicine, St. \\ George's University Medical School, Elizabeth, USA 3. Hematology and Medical Oncology, Rutgers Health/Trinitas \\ Regional Medical Center, Elizabeth, USA
}

Corresponding author: Hasham Saeed, saeed.hasham@outlook.com

\begin{abstract}
Felty syndrome (FS), an uncommon manifestation seen in patients with rheumatoid arthritis (RA), usually presents as a triad of erosive arthritis, splenomegaly, and neutropenia. It is extremely rare for RA to present as FS or develop after initially presenting as neutropenia and splenomegaly. In this report, we describe a case of a 55-year-old woman who initially presented with fever and vaginal pain. Her sepsis workup revealed genital herpes in the setting of leukopenia, with an incidental finding of splenomegaly on imaging. The patient was managed with filgrastim and valacyclovir. Two weeks later, she presented again with pleuritic chest pain and worsening leukopenia. This led to an extensive workup by the hematology team to diagnose and confirm the diagnosis of FS. We also engage in a review of the existing literature of such cases and emphasize the importance of serological testing for RA in patients with leukopenia and splenomegaly, even in the absence of joint symptoms or prior diagnosis of RA. The management should be guided towards treating the infection, correcting the neutropenia, and treating the underlying chronic disease.
\end{abstract}

Categories: Internal Medicine, Rheumatology, Hematology

Keywords: felty syndrome, rheumatoid arthritis, gsf refractory leukopenia, neutropenia, non-articular felty syndrome

\section{Introduction}

Felty syndrome (FS) is a rare complication of rheumatoid arthritis (RA), which is seen in patients with seropositive RA. The lifelong prevalence of FS is approximately 1-3\% [1]; women account for $60-80 \%$ of the total patient population, with an average age of onset in the late 30s-early 40s.

Patients who present with FS usually have deforming arthritis due to years of suffering from RA. However, this is not always the case as there have been a few case reports of FS presenting in patients without clinical evidence of arthropathy [2]. In this report, we describe a similar case with an atypical presentation of FS and the therapies used in the management.

Review began 07/22/2021 Review ended 08/09/2021 Published 08/15/2021

\section{๑) Copyright 2021}

Saeed et al. This is an open access article distributed under the terms of the Creative Commons Attribution License CC-BY 4.0., which permits unrestricted use, distribution, and reproduction in any medium, provided the original author and source are credited.
This article was previously presented as a poster at the 2021 Trinitas Research Day Conference on March 31, 2021.

\section{Case Presentation}

The patient was a 55-year-old Brazilian woman with no past medical history who presented to the emergency department with complaints of vaginal pain for two weeks. The symptoms had started as mild vaginal swelling and ulcers, which had then progressed to vaginal and lower abdominal pain, intermittent high-grade fever, nausea, and vomiting. Initial vital signs were significant for a temperature of $101.1{ }^{\circ} \mathrm{F}$, a pulse of 114/minute, respiratory rate of 18 /minute, and blood pressure of 77/43 $\mathrm{mmHg}$. Physical examination showed tenderness in the hypogastric and pelvic regions and whitish clustered vesicular lesions on the left labia minora and fourchette typical of genital herpes. Blood tests revealed a white blood cell (WBC) count of $1,100 / \mathrm{mm}^{3}(1.1 \mathrm{~K} / \mu \mathrm{l})$ with an absolute neutrophil count (ANC) of 30/mm $\mathrm{m}^{3}(0.03 \mathrm{~K} / \mu \mathrm{l})$.

A sepsis workup consisting of urine, blood, and vaginal cultures, and a CT scan of the abdomen were obtained to evaluate for septic shock. Norepinephrine infusion was initiated as the patient's hemodynamic instability was refractory to intravenous fluid hydration. The patient was started on broad-spectrum antibiotics and valacyclovir and was transferred to the intensive care unit for further management.

The septic workup revealed a diagnosis of genital herpes. Valacyclovir and norepinephrine infusions were continued until the patient was hemodynamically stable. The CT scan of the abdomen showed splenomegaly measuring up to $13.7 \mathrm{~cm}$ in the anteroposterior dimension. Given the leukopenia, the patient was empirically started on granulocyte colony-stimulating factor (G-CSF), i.e., filgrastim. The WBC count improved to $6,700 / \mathrm{mm}^{3}(6.7 \mathrm{~K} / \mu \mathrm{l})$ following five days of treatment with filgrastim. The patient was discharged on oral valacyclovir with an outpatient follow-up appointment at the hematology clinic. 
Two weeks following discharge, the patient presented with new-onset right-lower-sided chest pain for three days. The pain was sudden-onset, continuous, sharp in quality, progressive and non-radiating, and was aggravated by deep inspiration. No articular or extra-articular symptoms were reported by the patient. Physical examination was unremarkable except for shallow breathing due to the pain. A chest X-ray was negative for pleural effusion, and hence a provisional diagnosis of pleuritis was made.

The laboratory results showed a WBC count of $1,500 / \mathrm{mm}^{3}(1.5 \mathrm{~K} / \mu \mathrm{l})$ with an absolute neutrophil count (ANC) of $90 / \mathrm{mm}^{3}(0.09 \mathrm{~K} / \mu \mathrm{l})$. Hence, the patient was placed on neutropenic precautions and was admitted for further evaluation.

\section{Investigations}

Blood work was performed to find out the cause of leukopenia. The complement levels were within normal limits. Serum antinuclear antibodies (ANA) and rheumatoid factor (RF) were positive with anti-cyclic citrullinated peptides (anti-CCP) antibody levels greater than 250 units, thus confirming the diagnosis of RA. $\mathrm{X}$-ray of the feet and hands did not show any erosions or degenerative changes. The anti-double-stranded DNA (anti-dsDNA) antibody test was negative. Inflammatory marker results were significant for erythrocyte sedimentation rate (ESR) of $38 \mathrm{~mm} / \mathrm{hr}$ and C-reactive protein (CRP) of $6 \mathrm{ng} / \mathrm{dl}$ (normal level: <1 ng/dl).

The hematology and oncology team was consulted, and a bone marrow aspiration biopsy was performed (before the initiation of G-CSF therapy), which showed 80-90\% hypercellular marrow with trilineage hematopoiesis and myeloid left shift. There was also a 5\% clonal T-cell population, positive for clonal T-cell receptor (TCR) gamma gene rearrangement. HTLV1 antibodies, flow cytometry for CD55 and CD59, and antiplatelet antibodies were negative. RBC fragility test and direct and indirect Coombs tests were also negative.

\section{Differential diagnosis}

The main differential diagnoses following the bone marrow results were FS or RA-associated T-cell large granular lymphocytic (T-cell LGL) leukemia. Both conditions have analogous clinical and bone marrow biopsy findings as they both result from a similar disease process. However, the absence of marrow lymphocytosis and identifiable LGL cells made T-cell LGL an unlikely diagnosis in this case.

\section{Treatment}

The patient was restarted on filgrastim $480 \mathrm{mcg}$, with only some improvement in WBC and ANC. Hence, oral prednisone $30 \mathrm{mg}$ twice daily was initiated since the patient had no active infection on this presentation. Significant improvement in WBC count was noted. Filgrastim was subsequently discontinued and the patient was managed with prednisone therapy until discharge (Table 1). Methotrexate was not initiated during the hospitalization as anti-CCP antibody results were not reported initially. 
In this patient, the neutropenia improved over five days of G-CSF therapy. However, it was transient, with neutropenia worsening within two weeks after discontinuing treatment. The response was even worse on the second admission (Table 1).

In the absence of an active infection, glucocorticoid is an alternative therapy in patients who do not respond to filgrastim. Glucocorticoid improves neutropenia and, thus, leukopenia by altering granulocyte kinetics through several mechanisms. First, it stimulates the bone marrow to release non-segmented neutrophils into the circulation. In addition, it causes demargination of neutrophils from the endovascular lining while delaying neutrophil apoptosis [15,16]. This results in a significant improvement in WBC count [17]. Due to its immunosuppressive effects, glucocorticoids serve as a bridge to improve WBC counts until patients can be transitioned to other therapies. Our patient responded well to glucocorticoid therapy initially and was later started on methotrexate therapy.

Alternative therapies, including GM-CSF and rituximab, have also been documented in cases of FS-related neutropenia refractory to G-CSF therapy $[7,18]$. Splenectomy could be considered as a last resort after the failure of the aforementioned therapies [19].

\section{Conclusions}

In the absence of articular disease, diagnosis of FS can be challenging and clinicians should maintain a high index of suspicion. Regarding its management, FS-related neutropenia can be refractory to hematopoietic growth factor therapy like filgrastim and, in the absence of an active infection, glucocorticoid therapy is a superior option in such patients.

\section{Additional Information}

\section{Disclosures}

Human subjects: Consent was obtained or waived by all participants in this study. Conflicts of interest: In compliance with the ICMJE uniform disclosure form, all authors declare the following: Payment/services info: All authors have declared that no financial support was received from any organization for the submitted work. Financial relationships: All authors have declared that they have no financial relationships at present or within the previous three years with any organizations that might have an interest in the submitted work. Other relationships: All authors have declared that there are no other relationships or activities that could appear to have influenced the submitted work.

\section{References}

1. Balint GP, Balint PV: Felty's syndrome. Best Pract Res Clin Rheumatol. 2004, 18:631-45. 10.1016/j.berh.2004.05.002

2. Chavalitdhamrong D, Molovic-Kokovic A, Iliev A: Felty's syndrome as an initial presentation of rheumatoid arthritis: a case report. Cases J. 2009, 2:206. 10.1186/1757-1626-2-206

3. Owlia MB, Newman K, Akhtari M: Felty’s syndrome, insights and updates. Open Rheumatol J. 2014, 8:12936. $10.2174 / 1874312901408010129$

4. Hellmich B, Csernok E, Schatz H, Gross WL, Schnabel A: Autoantibodies against granulocyte colonystimulating factor in Felty's syndrome and neutropenic systemic lupus erythematosus. Arthritis Rheum. 2002, 46:2384-91. 10.1002/art.10497

5. Aslam F, Cheema RS, Feinstein M, Chang-Miller A: Neutropaenia and splenomegaly without arthritis: think rheumatoid arthritis. BMJ Case Rep. 2018, 2018:bcr2018225359. 10.1136/bcr-2018-225359

6. Liu X, Loughran TP Jr: The spectrum of large granular lymphocyte leukemia and Felty's syndrome . Curr Opin Hematol. 2011, 18:254-9. 10.1097/MOH.0b013e32834760fb

7. Wagner DR, Combe C, Gresser U: GM-CSF and G-CSF in Felty's syndrome . Clin Investig. 1993, 71:168-71. 10.1007/BF00180001

8. Rashba EJ, Rowe JM, Packman CH: Treatment of the neutropenia of Felty syndrome. Blood Rev. 1996, 10:177-84. 10.1016/s0268-960x(96)90024-7

9. Newman KA, Akhtari M: Management of autoimmune neutropenia in Felty's syndrome and systemic lupus erythematosus. Autoimmun Rev. 2011, 10:432-7. 10.1016/j.autrev.2011.01.006

10. Akhtari M, Waller EK: Neutropenias in Felty's syndrome and systemic lupus erythematosus. Twenty Years of G-CSF. Milestones in Drug Therapy. Molineux G, Foote M, Arvedson T (ed): Springer, Basel, Switzerland; 2012. 1:381-91. 10.1007/978-3-0348-0218-5_20

11. Fiechtner JJ, Miller DR, Starkebaum G: Reversal of neutropenia with methotrexate treatment in patients with Felty's syndrome. Correlation of response with neutrophil-reactive IgG. Arthritis Rheum. 1989, 32:194201. 10.1002/anr.1780320212

12. Narváez J, Domingo-Domenech E, Gómez-Vaquero C, et al.: Biological agents in the management of Felty's syndrome: a systematic review. Semin Arthritis Rheum. 2012, 41:658-68. 10.1016/j.semarthrit.2011.08.008

13. Hellmich B, Schnabel A, Gross WL: Treatment of severe neutropenia due to Felty's syndrome or systemic lupus erythematosus with granulocyte colony-stimulating factor. Semin Arthritis Rheum. 1999, 29:82-99. 10.1016/s0049-0172(99)80040-7

14. Stanworth SJ, Bhavnani M, Chattopadhya C, Miller H, Swinson DR: Treatment of Felty's syndrome with the haemopoietic growth factor granulocyte colony-stimulating factor (G-CSF). QJM. 1998, 91:49-56. 


\section{Cureus}

10.1093/qimed/91.1.49

15. Shoenfeld Y, Gurewich Y, Gallant LA, Pinkhas J: Prednisone-induced leukocytosis. Influence of dosage, method and duration of administration on the degree of leukocytosis. Am J Med. 1981, 71:773-8.

10.1016/0002-9343(81)90363-6

16. Smith MD, Ahern MJ, Brooks PM, Roberts-Thomson PJ: The clinical and immunological effects of pulse methylprednisolone therapy in rheumatoid arthritis. III. Effects on immune and inflammatory indices in synovial fluid. J Rheumatol. 1988, 15:238-41.

17. Bishop CR, Athens JW, Boggs DR, Warner HR, Cartwright GE, Wintrobe MM: Leukokinetic studies. 13. A non-steady-state kinetic evaluation of the mechanism of cortisone-induced granulocytosis. J Clin Invest. 1968, 47:249-60. 10.1172/JCI105721

18. Sarp U, Ataman S: A beneficial long-term and consistent response to rituximab in the treatment of refractory neutropenia and arthritis in a patient with Felty syndrome. J Clin Rheumatol. 2014, 20:398. 10.1097/RHU.0000000000000175

19. Hanrahan EM, Miller SR: Effect of splenectomy in Felty's syndrome . JAMA. 1932, 99:1247-9. 10.1001/jama.1932.02740670035010 